\title{
Electron Microscopic Studies of Nerve Endings in the Mucous Membrane of the Human Intestine*
}

\author{
By \\ Ryohei Honjin, Akira Takahashi and Yoshiaki Tasaki \\ Department of Anatomy, School of Medicine, \\ University of Kanazawa, Kanazawa \\ (Director: Prof. Dr. Ryohei Honjin)
}

The structural characteristics of the terminal ramifications of the autonomic nervous system in the mucous membrane of the intestine and the relationship between nerve terminations and innervated cells in the mucous membrane have been controversial problem for many years. Notwithstanding the excellent efforts of many researchers with light microscopy, our present knowledge concerning these subjects remains obscure. This may be ascribed to the difficulty in identifying the fine terminal nerve processes and their relationship to every innervated component in the mucous membrane, owing largely to the unreliability of the usual methods of staining nerves and to the relatively low resolving power of the light microscope. Many results obtained with light microscopy and criticisms of these are summarized in several thorough reviews by R a món y C a ja I (1911), H i l l (1927), S t öh r $(1928,1957), \mathrm{K} \mathrm{un} \mathrm{tz}$ (1949) and Me y ling (1953).

Recently, much valuable information on the structural organization of nervous tissue, including the terminal nerve endings which form synaptic junctions with several kinds of post-synaptic structures, has been secured by successful application of the high resolving power of the electron microscope and improved fixing, embedding and thin sectioning methods. The purpose of the present paper is to report the occurrence and characteristics of the fine structure of autonomic nerve endings in the mucous membrane of the human intestine, utilizing the electron microscope with thin sections.

* This investigation was supported in part by Research Grant No. 7091 received by one of the authors (R. H.) from the Ministry of Education of Japan. 


\section{Materials and Methods}

Small pieces of human small intestine and appendix which were removed from patients in operations for enterostenosis and appendicitis were used. Following removal, the materials were immediately placed in a vial of fixative and immersed in ice bath for 2 hours. Veronal-acetate buffered $1 \%$ osmium tetroxide at $\mathrm{pH} 7.25$ was used as fixative. After fixation, the materials were washed in several changed of cold distilled water for 1 hour and dehydrated by passage through a graded series of ethanol and then embedded in styrenemethacrylate ( $\mathrm{Ku} \mathrm{shida,1961).} \mathrm{Sections} \mathrm{were} \mathrm{cut} \mathrm{with} \mathrm{a} \mathrm{JUM-5}$ ultra-microtome using glass knife and mounted on electron microscope slit grids covered with carbon film. They were stained by sodium hydroplumbite method of $\mathrm{K}$ a r n o v s k y (1961) and examined using an HU-11 electron microscope equipped with a $20 \mu$ objective aperture.

\section{Observations}

Nerve bundles seen in the submucous plexus are composed of unmyelinated axons of varying sizes and number. Some of the large bundles may contain thirty or more axons, as their course is from the submucous layer to the muscularis mucosae (Fig. 1). Some of the small bundles within the muscularis mucosae contain only a few axons (Figs. 4, 5). In the propria of mucosae, the nerve bundle usually becomes slender by branching and the number of axons in a bundle decreases (Figs. 2, 3). Unmyelinated axons are usually suspended with mesaxons in the $\mathrm{Schwann}$ cell and isolated from the surface of the bundle by a complete investment in the $\mathrm{Sch}$ $\mathrm{w}$ a $\mathrm{n} \mathrm{n}$ membrane and cytoplasm. Generally speaking, each axon is hung by one mesaxon which retains its connection with the $\mathrm{Sch}$ w a $n$ cell surface membrane, and often two or more axons are held in common by one and the same mesaxon (Fig. 1). This tendency becomes more marked in the terminal part of the nerve bundle near the effector (Fig. 3). There is one group of several axons which touch one another at their axon membranes without the intervening cytoplasm of the $\mathrm{Schwann}$ cell. The various forms of sections suggest that they are branches derived from one axon.

Each $\mathrm{Schwann}$ cell unit containing axons is affixed by a basement membrane at its outer surface and many collagen fibrils surround the $\mathrm{Schw}$ a n $\mathrm{n}$ cell unit. The cytoplasm of $\mathrm{Schw}$ an 
cells appears pale and contains sparse, fine granules, mitochondria and intracytoplasmic membrane structures. The axons in the nerve bundle contain many neurofilaments approximately $100 \AA$ in diameter, tubular structures of the smooth-surfaced endoplasmic reticulum and mitochondria. The axoplasm is limited by an axon membrane about $80 \AA$ in thickness, which is usually enveloped by a Sch w a n $\mathrm{n}$ membrane formed by elongation of the mesaxon. Even in rather large nerve bundles in the muscularis mucosae, some of the axons which lie along the outer surface of the bundle are only partially covered by the $\mathrm{Sch}$ wan membrane; they lie just beneath the basement membrane (Fig. 1). In these instances, the axons more or less expand and sometimes, though not commonly, contain many membrane-bound vesicles which are very similar to the synpatic vesicles (Fig. 1, arrows). This part of the axon is only a short distance from the vesiculated large expansion of the terminal axon.

Within the muscularis mucosae the small nerve bundles are located in the spaces between the smooth muscle cells. Fig. 4 shows a cross section of a small nerve bundle containing several axons, which in all probability would have appeared as a fine bundle of nerve fiber when stained with methylene blue or silver for examination by light microscopy ( $\mathrm{H}$ o $\mathrm{n} \mathrm{j}$ i $\mathrm{n}, 1951)$. This kind of fine nerve bundle corresponds to the fine nervous strand termed 'neural terminal net' (Hon j i n, 1956a, b; Hon ji n, I z u m i and $\hat{O}$ s u gi, 1959). Even here there is considerable variation both in the diameter of the axons and their internal structure. In Fig. 4, some of the axons show only neurofilaments and small mitochondria and others contain a small number of membrane-bound vesicles besides neurofilaments, while one axon seen in the lower right part of the bundle in the photograph is markedly swollen in diameter and is filled with a multitude of membrane-bound vesicles and several mitochondria. This part of axon is termed 'vesiculated nerve process.' The vesicles and their distribution in the vesiculated nerve process are identical in shape with the synaptic vesicles whose existence is a characteristic feature of the synaptic junction found in many other parts of the body.

The vesicles found here can be classified into two kinds, those containing dense central granules and those without granules. The former are termed 'granular' synaptic vesicles and the latter 'agranular' ones according to assortment by $\mathrm{R}$ i c ha r d s o n (1962). Both kinds of vesicles are limited by a thin membrane approximately 40 to $50 \AA$ in thickness and show round or slightly oval profiles. 
The granular vesicles are few in number and are present deen within the vesiculated process. Their average diameter is abou $660 \AA$ with a range of 500 to $900 \AA$. The diameter of the electrondense central granules in the granular vesicles ranges from 160 to $250 \AA$. The agranular vesicles are much more numerous than the granular vesicles and more uniform in size. Their diameter ranges from 300 to $450 \AA$ with an average of $350 \AA$. The agranular vesicles contain an electron lucid substance which has a density slightly greater than that of the substance surrounding the vesicles. They are found everywhere in the vesiculated nerve process and nearly always densely crowded. Near the surface of the vesiculated nerve process there are found only agranular vesicles. The mitochondria in the vesiculated nerve process have an approximate diameter of $0.15 \mu$. Fig. 5 shows a vesiculated nerve process which has almost the same features as the one seen in Fig. 4, except that the nerve process seen in Fig. 5 is somewhat larger in size and contain many mitochondria.

The vesiculated nerve process is bounded by a plasma membrane approximately $80 \AA$ thick. As a whole, it is relatively large in size and its diameters in sections range from 1 to $20 \mu$. The vesiculated nerve process found in the muscularis mucosae corresponds to the varicosities which are often seen along the fine nerve bundles in the mast peripheral part of the autonomic nervous system stained with methylene blue or silver for examination by light microscopy (H o n j i n, 1951, 1956a, b). These vesiculated nerve processes lie on the outer surface of the fine nerve bundle; the $\mathrm{Sch}$ w a $\mathrm{n}$ cell attaches itself to the vesiculated nerve process only on one side. A large part of the surface of the vesiculated nerve process is naked and shows juxtaposition to the surface of the smooth muscle cell (Figs. 4, 5). The vesiculated nerve process and the muscle cell are separated by an interval ranging from 2,000 to $3,000 \AA$ in width. The basement membranes which cover the surfaces of both the vesiculated nerve process and muscle cell extend into this gap. There is found a relatively wide space between the two basement membranes where a less electron-dense substance and collagen fibrils are present. However, in many cases, no connective tissue cell appears to extend into this gap. A small number of pinocytotic vesicles are present immediately beneath the plasma membrane of the muscle cell. Neither increased density of the apposed membranes of both the vesiculated nerve process and muscle cell nor complicated folds in the plasma membrane of the muscle cell can be seen. 
A great number of sections of muscularis mucosae exceeded 600 photographs were examined in this study, nevertheless we could not find any closer apposition (less than 1,000 $\AA$ in width) between the vesiculated nerve process and the muscle cells in the muscularis mucosae. Text-fig. 1 is a diagramatic representation of a vesiculated nerve process in the muscularis mucosae.

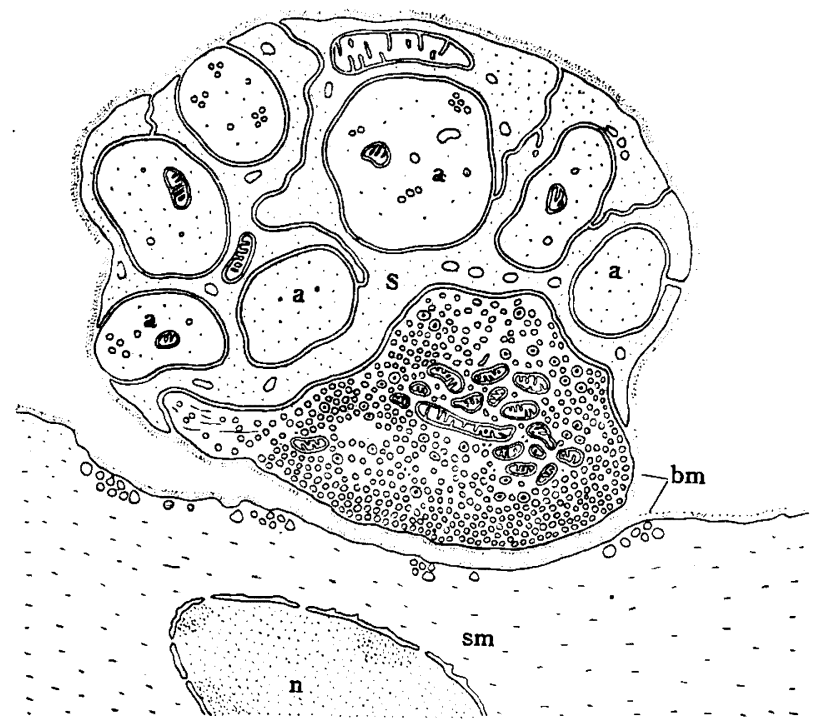

Text-fig. 1. Diagramatic representation of a vesiculated nerve process which lies on the outer surface of the small nerve bundle in the muscularis mucosae of the human intestine. a, axon; ae, vesiculated nerve process; bm, basement membrane; $\mathrm{n}$, nucleus; $\mathrm{S}, \mathrm{Sch}$ wan cell; $\mathrm{sm}$, smooth muscle cell. The covering of the $\mathrm{Schw}$ an $\mathrm{n}$ cell on the vesiculated nerve process becomes incomplete on one side. The vesiculated nerve process is in juxtaposition to the smooth muscle cell. A large number of agranular synaptic vesicles, several granular synaptic vesicles and mitochondria are present in the vesiculated nerve process. The interval between the vesiculated nerve process and smooth muscle cell is relatively large. The basement membrane extend's into this interval.

Fig. 6 shows a nerve bundle which contains several axons of various characters and lies on the inner surface of the muscularis mucosae. Some of the axons contain only neurofilaments and mitochondria, while others expose themselves partly to the outer surface of the bundle and contain many synaptic vesicles similar to those described above. One vesiculated nerve process seen in the upper part of the photographic field, however, contains many small dense 
granules approximately 100 to $200 \AA$ in diameter, several vesicles and a mitochondrion. This axonal process is apposed to the smooth muscle cell in the right part of the field. It may be supposed that this vesiculated nerve process is in a depleted state; it may have just discharged the contents of its vesicles.

In the propria of mucosae, the nerve bundles are relatively slender. The course of some of them is near the inner surface of the muscularis mucosae as mentioned above, while others run between the crypts of the intestinal glands to proceed toward the intestinal villi (Fig. 2, 3). As the axon near the terminal part, they begin to contain the sparsely distributed synaptic vesicles and gradually lose the sheath of the $\mathrm{Sch}$ w a $\mathrm{n}$ cell. Ultimately, the axon expands and contains many synaptic vesicles to assumes a vesiculated nerve process. It is supported by the $\mathrm{Sch}$ w a n cell on only one side. As shown in Fig. 9, the vesiculated nerve process of this kind is held by the process of the $\mathrm{Schw}$ a $\mathrm{n} \mathrm{nell}$ on one side, while it clearly shows close apposition to a proper cell thought to be an interstitial cell of $\mathrm{Cajal}$ on the other side. Sometimes it has been observed that the vesiculated nervo process retains its position on the outer surface of the small nerve bundle and directly forms the synaptic junction with the interstitial cell of $\mathrm{Cajal}$ (Fig. 8). In these instances, the vesiculated nerve process and the interstitial cell of $\mathrm{Cajal}$ are separated by an interval ranging from 120 to $200 \AA$ in width. Basement membrane material does not extend into the synaptic cleft.

This kind of vesiculated nerve process contains a uniform population of only agranular synaptic vesicles which show centers filled with an evenly dispersed material and are seen in clusters polarized toward the closely apposed membranes of the junction (Fig. 8). The synaptic membranes of both the vesiculated nerve process and the interstitial cell of $\mathrm{Cajal}$ lack specialization at the point of contact, except for the increased density of the contiguous membranes. Granular vesicles are not found in this kind of vesiculated nerve process. The interstitial cells of $\mathrm{Cajal}$ contain many large and small smooth-surfaced vacuoles and rough-surfaced endoplasmic reticulum in their cytoplasm. They have slender cytoplasmic processes which lie between the nerves and the capillaries and the other cells of propria of the mucosae. The structural relationship between the vesiculated nerve process and the interstitial cell of $\mathrm{Cajal}$ found in the propria is completely different from that in the vesiculated nerve process in the muscularis mucosae, 
in the width of the synaptic cleft, in the characteristics of the synaptic vesicles and in the size of the vesiculated nerve process as a whole. Text-fig. 2 is a diagramatic representation of the type of synaptic junction found in the propria of mucosae.

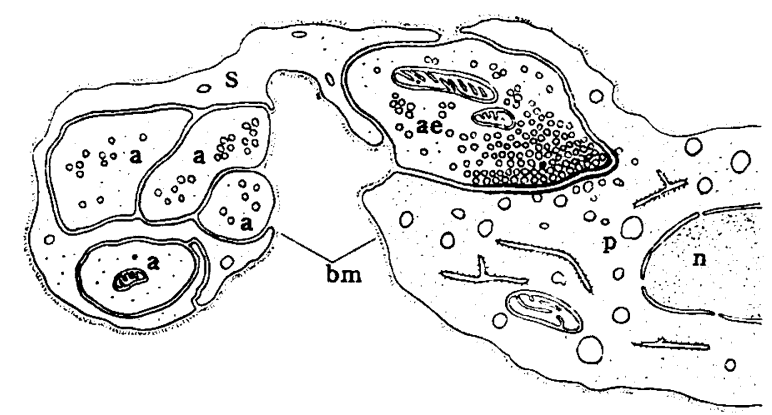

Text-fig. 2. Diagramatic representation of a vesiculated nerve process which lies in close apposition to an interstitial cell of $\mathrm{Cajal}$ in the propria of mucosae of the human intestine. a, axon; ae, vesiculated nerve process; bm, basement membrane; $\mathrm{n}$, nucleus; $\mathrm{S}, \mathrm{Sch}$ wan $\mathrm{n}$ cell; $\mathrm{p}$, interstitial cell of $\mathrm{Cajal}$. Close apposition between the vesiculated nerve process and the interstitial cell is shown. The vesiculated nerve process contains many agranular synaptic vesicles which appear as a cluster polarized toward the closely apposed synaptic membranes. The pre- and post-synaptic membranes show an increased electron density at the junction.

\section{Discussion}

Much has been written about the fine structure of many kinds of synaptic junctions investigated by electron microscopy. There has been, however, no report of the ultrastructure of the nerve terminations in the mucosae of the gastrointestinal tract. The present paper clearly demonstrates the occurrance and characteristics of two kinds of vesiculated nerve processes in the human intestinal mucosae: one in the muscularis mucosae and the other in the propria of mucosae. They are different from each other in structural characteristics such as the size of the expansion, type of synaptic vesicles and structural relationship to the effector cells.

The vesiculated nerve processes found in the muscularis mucosae are different from those found in the muscle layer of several organs of a variety of animals as reported by previous researchers. C e s a , Edwards and R u ska (1957) suggested that the axon in the urinary bladder, uterus and gall bladder of mice shows a close re- 
lationship to the smooth muscle cells. Y a m a m o to (1960) described the single nerve ending in the muscle layer of the human appendix, but the endings he investigated were devoid of synaptic vesicles. On the other hand, G a $\mathrm{n}$ s l e $\mathrm{r}$ (1961) could not find any naked axons in the muscle layers of guinea pig intestine; he denied the existence of specific structures for synapses. Recently, R i c h a r d s o n (1962) and $\mathrm{Th}$ a e mert (1963) have studied the nerve endings in the muscle layers of the vas deferens, gastrointestinal tract and urinary bladder of rats and demonstrated that the individual naked neurits ultimately pass into grooves on the surface of the smooth muscle fibers to form vesiculated nerve processes in which there is a close apposition between the axon and muscle cell membranes with a cleft from 160 to $300 \AA$ in width.

According to the present study, the vesiculated nerve process in the muscularis mucosae lie along the outer surface. of the fine nerve bundle as large expansions which contain a large number of synaptic vesicles and are apposed to the outer surface of the smooth muscle cells with a large interval of about 2,000 to $3,000 \AA$ in width. The numerical value for the width of this interval is large as compared with those for the endings in the muscle layers of vas deferens, gastrointestinal tract and urinary bladder obtained by $\mathrm{R}$ i c hardson (1962) and $\mathrm{Th}$ a e mert (1963). But is well known, the synaptic clefts found in other kinds of synapses are not always of a constant width. The gaps between the surface membranes of both the pre- and post-synaptic neurons in the central and peripheral nervous system are 120 to $200 \AA$ in width (De Robertis and Bennett, 1955; P a lay, 1958; D e R obertis, 1958, 1959 ; Richardson, 1958; Gray, 1961; Gray and Whittaker, 1962 ; $\mathrm{H}$ a m l y n, 1962; H o n j in, 1962; B l a ckstad and Da h l, 1962), while the gap in the motor end-plate is from 500 to $650 \AA$ in width (Robertson, 1956; A nderson-Cedergren, $1959 ; \mathrm{De}$ $\mathrm{H}$ a r ve n and Coërs, 1959 ; R e ger, 1959, 1961 ; B ir ks, Hux le y and $\mathrm{Katz}, 1960 ; \mathrm{Z} \mathrm{a} \mathrm{cks}$ and $\mathrm{Blumber} \mathrm{m}, 1961 ; \mathrm{H}$ o n j i n, 1962 ; Orfanos, 1962; Revel, 1962). In the case of the motor endplate, the synaptic cleft usually contains the basement membrane and at times the small processes of the $\mathrm{Sch}$ w a n $\mathrm{n}$ cell (Birks, $\mathrm{H} \mathrm{uxle} \mathrm{y}$ and $\mathrm{Katz}, 1960$ ), and the post synaptic membrane shows complicated junctional folds. These facts would indicates that the close packing of the pre- and post-synaptic membranes in the junction and the absence of the basement membrane in the cleft are not essential features of all synaptic junctions. However, the 
synaptic nerve endings always contain many small vesicles. The vesiculated nerve processes in the muscularis mucosae demonstrated here also contain a large number of typical synaptic vesicles which are of two types, agranular and granular. Attention must now again be focused on these vesicles in relation to the mode of formation and discharge of the miniature end-plate potentials in smooth muscle as discovered by $\mathrm{B} \mathrm{u} \mathrm{r} \mathrm{n} \mathrm{s} \mathrm{to} \mathrm{ck}$ and $\mathrm{H} \mathrm{ol} \mathrm{m} \mathrm{a} \mathrm{n} \mathrm{(1961),} \mathrm{though}$ the morphological evidence is likely to be equivocal. The synaptic vesicles are now generally thought to have a relation to releasing the chemical mediators in the synapse. The chemical transmitter substance released from the vesiculated nerve process in the muscularis mucosae may flow out diffusely into the considerably wide interval between the nerve process and muscle cell and into the intermuscular connective tissue space. The vesiculated nerve process in the muscularis mucosae demonstrated here would represent the possibility of presence of the diffuse innervation by 'Synapse auf Distanz' which was hypothetically suggested by J a b o n e r o (1959). The same possibility of the diffuse neuro-muscular innervation has been pointed out by $\mathrm{Faw}$ cet $\mathrm{t}$ and $\mathrm{Sel}$ b y (1958) in electron microscopy of the turtle atrium.

The vesiculated nerve processes in the propria of mucosae are relatively small in size. They, however, show a close apposition to the interstitial cells of $\mathrm{Caja}$. Their synaptic cleft is about 120 to $200 \AA$ in width. Other characteristics of this synaptic junction are quite similar to those in synapses in the central nervous system and peripheral ganglia. All the synaptic vesicles in this kind of vesiculated nerve process are of the granular type. Neither junctional folds of the post-synaptic membrane of the interstitial cell of $\mathrm{C} \mathrm{a} \mathrm{ja}$ nor the extension of the basement membrane into the synaptic cleft are found. The present finding would support the concept of the neuronal activity of the interstitial cell of $\mathrm{Cajal}$.

Characteristic membraneous vesicles containing an electron lucid core were named 'synaptic vesicles' by De R obertis and B ennett (1955). Based on the histochemical findings of cholinesterase in the synaptic junction of the motor end-plate by $\mathrm{Cou}$ tea u $(1955,1958)$, D e Robertis (1959) suggested that the synaptic vesicles are associated with acetylcholine or other chemical synaptic mediators. Recently, B a r r n e t t (1962) also demonstrated the fine structural localization of acetylcholinesterase at the myoneural junction in detail. On the other hand, the structures isolated by centrifugation or revealed in electron micrographs of the cells 
of the adrenal medulla, sympathetic nerves and carotid body are also membraneous vesicles, but they contain an electron dense centra. granule (B laschko, $\mathrm{H}$ age n and $\mathrm{Welch}, 1955$; Schümann, 1958: von Euler, 1958; Ross, 1959). This granulated type of synaptic vesicles is considered to have relation to the chemical mediator related to the sympathetic transmission, and has been observed electron microscopically in several nerve endings (D e R obertis and De Iraldi, 1961; R i chards on, 1962; Grillo and $\mathrm{Palay}, 1962$ ). The present observation indicates that the vesiculated nerve process found in the muscularis mucosae contains both agranular and granular vesicles, while that found in the propria contains agranular vesicles only. One interesting problem for researchers will be to make distinctions between these two types of vesicles or vesicles and other structures associated respectively with the cholinergic and adrenergic transmitters, as well as to conclude the physiological significance of both vesiculated nerve process found here. If the presumption may be allowed, the agranular vesicles may be related to acetylcholine and the granular vesicles to catechol amines. However, it would be premature to conclude that the two types of vesiculated nerve processes found in this study are efferent in function, because the afferent nerve endings also contain agranular vesicles and show similar characteristics (Engström and Wersäll, 1958; S jöstrand, 1958; Cauna and Ross, 1960; Smith and $\mathrm{Sjöstrand,} \mathrm{1961).}$ Identification of the endings as afferent or efferent warrants careful attention. If efferent, they may be sympathetic or parasympathetic, and furthermore, they may be accelerative or inhibitory. These problems, however, cannot be solved merely on the basis of the morphological evidence presented here.

\section{Summary}

The mucous membrane of the human small intestine and appendix were fixed in $1 \%$ osmium tetroxide buffered with veronal acetate $(\mathrm{pH} 7.25)$, embedded in styrene-methacrylate and, after sectioning, stained with sodium hydroplumbite for electron microscopy. The results obtained are as follows:

1. Nerve bundles entering the mucosae of the human small intestine and appendix divide into many fine branches, each consisting of several axons with a $\mathrm{Sch}$ w a $\mathrm{n}$ cell sheath covered with basement membrane. Each axon is usually hung by one mesaxon, 
but sometimes two or more axons are held in common one and the same mesaxon.

2. As the fine nerve bundles pass into the muscularis mucosae, some of the axons in the nerve bundle lose the covering of the $\mathrm{Schw}$ a $\mathrm{n}$ cell and are markedly swollen to form the vesiculated nerve processes which lie along the outer surface of the fine nerve bundle and are filled with a large number of agranular synaptic vesicles without granules, several granular vesicles containing dense granules and mitochondria. A large part of the surface of the vesiculated nerve process is naked and shows juxtaposition to the smooth muscle cells at a relatively large distance of 2,000 to $3,000 \AA$. The vesiculated nerve process of this kind would represent the possibility of presence of the diffuse innervation in the muscularis. mucosae by 'Synapse auf Distanz' suggested by J a bo n e r o.

3. In the propria of mucosae the fine nerve bundles lie between the vessels, intestinal glands and proper cells. The fine axons in the nerve bundle lose their sheath and pass into grooves on the surface of the interstitial cells of $\mathrm{Caja} /$ to form slightly swollen expansions which contain many agranular synaptic vesicles. Vesiculated nerve processes of this kind involve a close apposition of the surface membrane of the nerve process and that of the interstitial cell. They are separated by an interval ranging from 120 to $200 \AA$ in width and show an increased density in the contiguous. field of the synaptic junction. The agranular vesicles appear as a cluster polarized toward the closely apposed synaptic membranes. Basement membrane material does not extend into the cleft of this type of synaptic junction.

4. The nature of both types of vesiculated nerve processes found here with reference to the transmitter substances, acetylcholine and catechol amines, which are thought to be related to the agranular and granular synaptic vesicles respectively, are briefly discussed.

\section{Bibliography}

A nders o n-C edergren, E. 1915 Ultrastructure of motor end-plate and sarcoplasmic components of mouse skeletal muscle fiber. J. Ultrast. Research, suppl. $1: 1-191$.

B a r r n e t t, R. J. 1962 The fine structural localization of acetylcholinesterase at the myoneural junction. J. Cell Biol., $12: 247-262$.

B irks, R., H u x le y, H.E. and $\mathrm{Katz}, \mathrm{B}$. 1960 The fine structure of the neuromuscular junction of the frog. J. Physiol., London, 150: 134-144. 
B lackstad, T.W., and Dahl, H.A. 1962 Quantitative evaluation of structures in contact with neuronal somata. Acta Morphol. Neerl.-Scand., 4: 329-343.

Bla schko, H., $\mathrm{Hagen}, \mathrm{P}$. and Welch, A.D. 1955 Observations on the intra cellular granules of the adrenal medulla. J. Physiol., London, $129: 27-49$.

Burnstock, G., and Holman, M.E. 1961 The transmission of excitation from autonomic nerve to smooth muscle. J. Physiol., London, 155 : 115-133.

C a u n a, N., and Ross, L.L. 1960 The fine structure of Me is s ner's touch corpuscles of human finger. J. Biophys. Biochem. Cytol., $8: 467-482$.

Ces a r, R., Edwards, G.A. and Rus ca, H. 1957 Architecture and nerve supply of mammalian smooth muscle tissue. J. Biophys. Biochem. Cytol., 3: 867-878.

Cout e a u , R. 1955 Localization of cholinesterases at neuromuscular junctions. Internati. Rev. Cytol., $4: 335-375$.

1958 Morphological and cytochemical observations on the post-synaptic membrane at motor end-plates and ganglionic synapses. Exp. Cell Res., suppl. $5: 294-322$.

De Harven, E., and Coërs, C. 1959 Electron microscope study of the human neuromuscular junction. J. Biophys. Biochem. Cytol., 6: 7-10.

De Robertis, E.D.P. 1958 Submicroscopic morphology and function of the synapse. Exp. Cell Res., suppl. $5:$ 347-369.

1959 Submicroscopic morphology of the synapse. Internatl. Rev. Cytol., 8: 61-96.

De Robertis, E.D.P., and Bennett, H.S. 1955 Some features of the sub-microscopic morphology of synapses in frog and earthworm. J. Biophys. Biochem. Cytol., $1: 47-58$.

De Robertis, E.D.P., and De Iraldi, A.P. 1961 Plurivesicular secretory processes and nerve endings in the pineal gland of the rat. J. Biophys. Biochem. Cytol., 10:361-372.

Engström, H., and Wersä 11, J. 1958 The ultrastructural organization of the organ of Corti and of the vestibular sensory epithelia. Exp. Cell Res., suppl. 5: 460-492.

Fawcett, D.W., and Selby, C.C. 1958 Observations on the fine structure of the turtle atrium. J. Biophys. Biochem. Cytol., 4: 63-72.

G a n s l e r, H. 1961 Phasenkontrast- und elektronenmikroskopische Untersuchungen zur Innervation der glatten Muskulatur. Acta Neuroveget., Wien, 22 : 192-211.

Gray, E.G. 1961 The granule cells, mossy synapses and Purkinje spine synapses of the cerebellum: Light and electron microscope observations. J. Anat., London, $95: 345-356$.

Gray, E.G., and Whittaker, V.P. 1962 The isolation of nerve endings from brain: An electron microscopic study of cell fragments derived by homogenization and centrifugation. J. Anat., London, 96:79-88.

Gri 11 o, M. A., and Pa 1 a y, S.L. 1962 Granule containing vesicles in the autonomic nervous system. Vth Internatl. Congress for Electron Microsc., 2: U-1.

$\mathrm{H} \mathrm{a} \mathrm{m} \mathrm{ly} \mathrm{n,} \mathrm{L.H.} 1962$ The fine structure of the mossy fibre endings in the hippocampus of the rabbit. J. Anat., London, 96, 112-119.

Hi1l, C. J. 1927 A contribution to our knowledge of the enteric plexuses. Philos. Trans. Roy. Soc. London, Series B, 215: 355-387.

$\mathrm{H}$ o n jin, R. 1951 Studies on the nerve endings in the small intestine. Cytol. and Neurol. Stud., $9: 1-15$.

1956 a The innervation of the pancreas of the mouse, with special reference to the structure of the peripheral extension of the vegetative nervous system. J. Comp. Neurol., 104 : 331-371. 
$1956 \mathrm{~b}$ On the nerve supply of the lung of the mouse, with special reference to the structure of the peripheral vegetative nervous system. J. Comp. Neurol., 105 : $587-625$.

1962 Electron microscopy of synapses. Progr. Neurol. Stud., 6: 873-892. (Japanese with English summary).

Hon j i n, R., I z u m i, S. and Ôsugi. H. 1959 The distribution and morphology of argentophile and argentophobe nerve cells in the myenteric plexus of the digestive tube of the mouse: A quantitative study. J. Comp. Neurol., 111:291-320.

Jabonero, V. 1959 Die plexiforme Synapse auf Distanz und die Bedeutung der sogenannten interkalären Zelle. Acta Neuroveg., Wien, $19: 276-302$.

Karnovsky, M.J. 1961 Simple methods for "staining with lead" at high pH in electron microscopy. J. Biophys. Biochem. Cytol., 11: 729-732.

Kuntz, A. 1947 Autonomic nervous system. 3rd ed. Lea and Febiger, Philadelphia.

$\mathrm{Kushida}, \mathrm{H} .1961$ A styrene-methacrylate resin embedding method for ultrathin sectioning. J. Electronmicroscopy, 10:16-19.

Meyling, H. A. 1953 Structure and significance of the peripheral extension of the autonomic nervous system. J. Comp. Neurol. 99 :495-543.

Orfanos, C. 1962 Zur Mikromorphologie der neuromuskulären Verbindung der afibrillär-tonischen Skeletmuskelfaser des Frosches (Rana temporaria L.). Z. Zellf., $56: 387-403$.

P a 1 a y, S.L. 1958 The morphology of synapses in the central nervous system. Exp. Cell Res., suppl. 5 : 275-293.

R a món y Ca ja l, S. 1911 Histologie du systeme nerveux de l'homme et des vertébrés. II, A. Maloine, Paris.

Reger, J.F. 1959 Studies on the fine structure of normal and denervated neuromuscular junctions from mouse gastrocnemius. J. Ultrast. Research, 2 : 269-282.

1961 The fine structure of neuromuscular junctions and the sarcoplasmic reticulum of extrinsic eye muscles of Fundulus heteroclitus. J. Biophys. Biochem. Cytol., 10 : suppl. 111-121.

Revel, J.P. 1962 The sarcoplasmic reticulum of the bat cricothyroid muscle. J. Cell Biol., $12: 571-588$.

Richardson, K.C. 1958 Electron microscopic observations on Auerbach's plexus in the rabbit, with special reference to the problem of smooth muscle innervation. Am. J. Anat., 103 : 99-135.

1962 The fine structure of autonomic nerve endings in smooth muscle of the rat vas deferens. J. Anat., London, $96: 427-442$.

Robertson, J.D. 1956 The ultrastructure of reptilian myoneural junction. J. Biophys. Biochem. Cytol., 2 :381-394.

Ros s, L. L. 1959 Electron microscopic observations of the carotid body of the cat. J. Biophys. Biochem. Cytol., 6 : 253-262.

Schü m a n n, H. J. 1958 Über die Verteilung von Noradrenalin und Hydroxytyamin in sympathischen Nerven (Milznerven). Arch. exp. Path. Pharmak., 234 : 17-25.

Sjöstrand, F.S. 1958 Ultrastructure of retinal rod synapses of the guinea pig eye as revealed by three-dimensional reconstructions. J. Ultrast. Research, 2 : $122-170$

S mith, C.A. and S jöstrand, F.S. 1961 Structure of the nerve endings on the external hair cells of the guinea pig cochlea as studied by serial sections. J. Ultrast. Research, 5 : 523-556.

Stöhr, Jr. Ph. 1928 Möllendorff's Handbuch der mikroskopische Anatomie des Menschen, IV/1, Springer, Berlin.

1957 Möllendorff's Handbuch der mikroskopische Anatomie des Men- 
schen, IV $/ 5$, Springer, Berlin.

Thaemert, J.C. 1963 The ultrastructure and disposition of vesiculated nerve processes in smooth muscle. J. Cell Biol., $16: 361-377$.

von Euler, U.S. 1958 The presence of the adrenergic neurotransmitters in intraaxonal structures. Acta Physiol. Scand., 43: 155-166.

Y a m a m ot o, T. 1960 Electron microscope investigation on the relationship between the smooth muscle cell of the Proc. vermiformis and the autonomic peripheral nerves. Acta Neuroveget., Wien., 21 : 406-425.

$\mathrm{Z}$ a cks, S.I. and B $1 \mathrm{u} \mathrm{m} \mathrm{berg,} \mathrm{J.M.} 1961$ Observations on the fine structure and cytochemistry of mouse and human intercostal neuromuscular junctions. J. Biophys. Biochem. Cytol., 10 : 517-528.

\title{
Explanation of Plates
}

\author{
Abbreviations \\ a: axon of the unmyelinated nerve fiber. \\ ae: vesiculated nerve process of the unmyelinated nerve axon. \\ $c$ : capillary in the propria of mucosae. \\ $\mathrm{n}$ : nucleus of the smooth muscle cell. \\ p: interstitial cell of Cajal in the propria of mucosae. \\ S: Schwann cell. \\ $\mathrm{sm}$ : smooth muscle cell. \\ Scale indicates $1 \mu$.
}

\section{Plate I}

Fig. 1. Electron micrograph of a cross section of a relatively large nerve bundle in the muscularis mucosae of the human small intestine. Many of the axons(a) in the bundle are suspended with the mesaxon in the $S c h$ wan cell( $(S)$. At places two or more axons are held in common by one and the same mesaxon. Note the axons which contain many small vesicles (arrows). The covering of Schwann cell becomes incomplete on one side of these axons. $\times 23,000$.

Fig. 2. Electron micrograph of a cross section of a relatively small nerve bundle in the propria of mucosae of the human small intestine. Some of the axons lose the covering of the $\mathrm{Sch}$ w a $\mathrm{n}$ cell on one side and lie in a depression of the $\mathrm{S} \mathrm{ch}$ w a $\mathrm{n}$ cell. They contain sparsely distributed small vesicles. $\times 23,000$.

Fig. 3. Electron micrograph of a cross section of a small nerve bundle in the propria of mucosae of the human small intestine. Two or four axons directly touching one another and enveloped in common by a $\mathrm{Sch}$ wan membrane are seen. $\times 23,000$. 
Plate I

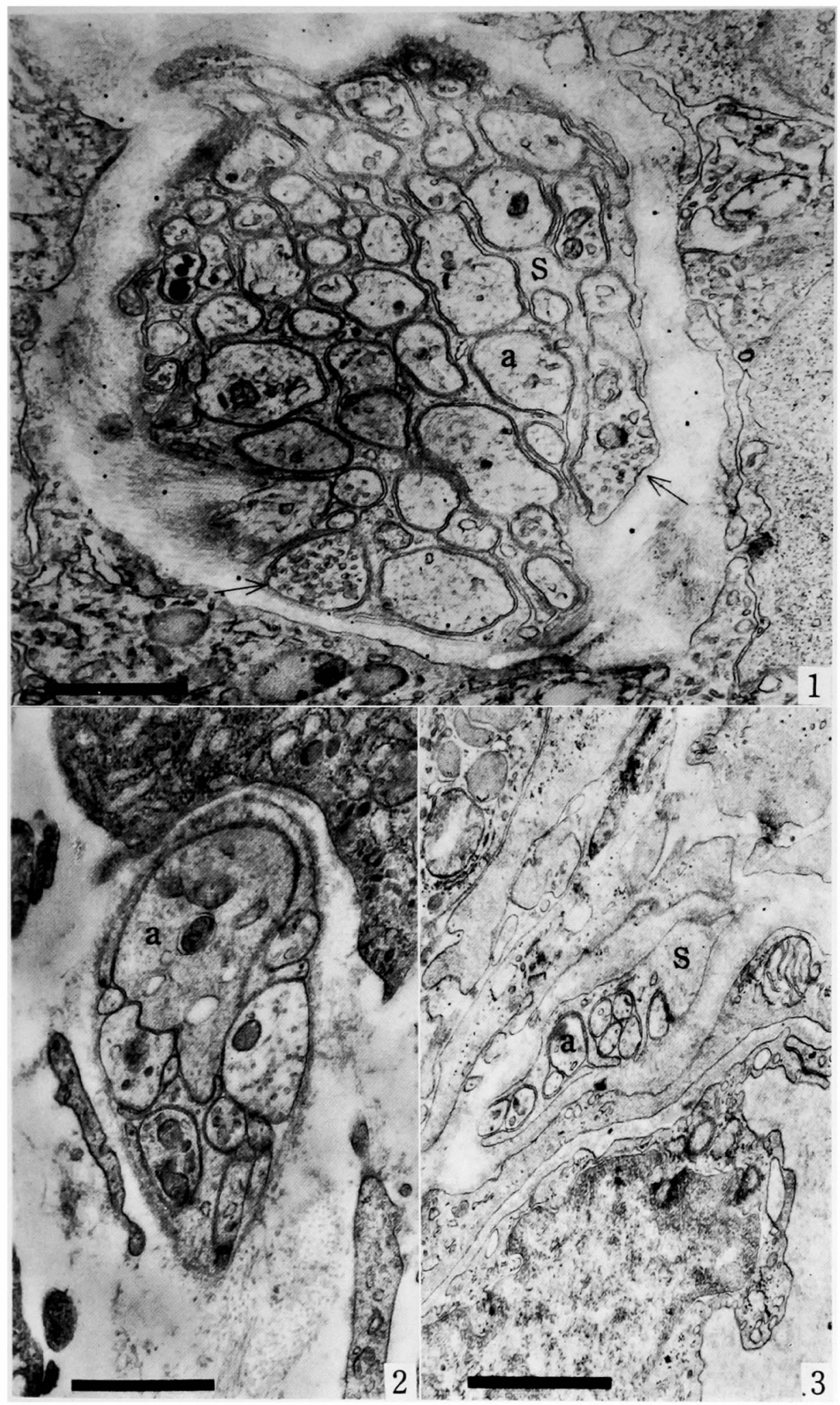

R. Honjin, A. Takahashi and Y. Tasaki 


\section{Plate II}

Fig. 4. Electron micrograph of a cross section of a relatively small nerve bundle within the muscularis mucosae of the human small intestine. One vesiculated nerve process (ae) lies on the outer surface of the nerve bundle. The covering of the $\mathrm{Schw}$ an $\mathrm{n}$ cell (S) is incomplete around this nerve process. A large number of agranular synaptic vesicles, several granular synaptic vesicles and mitochondria are present in this vesiculated nerve process (ae), which is in juxtaposition to the smooth muscle cell. There is a relatively wide distance between the surface membranes of both the vesiculated nerve process and the smooth muscle cell $(\mathrm{sm})$. The basement membrane and collagen fibrils extend into this space. $\times 30,000$.

Fig. 5. Electron micrograph of an oblique section of a vesiculated nerve process (ae) situated on the outer surface of a nerve bundle within the muscularis mucosae of the human small intestine. The vesiculated nerve process contains a large number of agranular synaptic vesicles, several granular synaptic vesicles and mitochondria. This vesiculated nerve process is situated along a slightly grooved surface of a smooth muscle cell $(\mathrm{sm})$ with a relatively wide interval of $2,000 \AA$ in width, into which the basement membrane extends. $\times 30,000$. 
Plate II
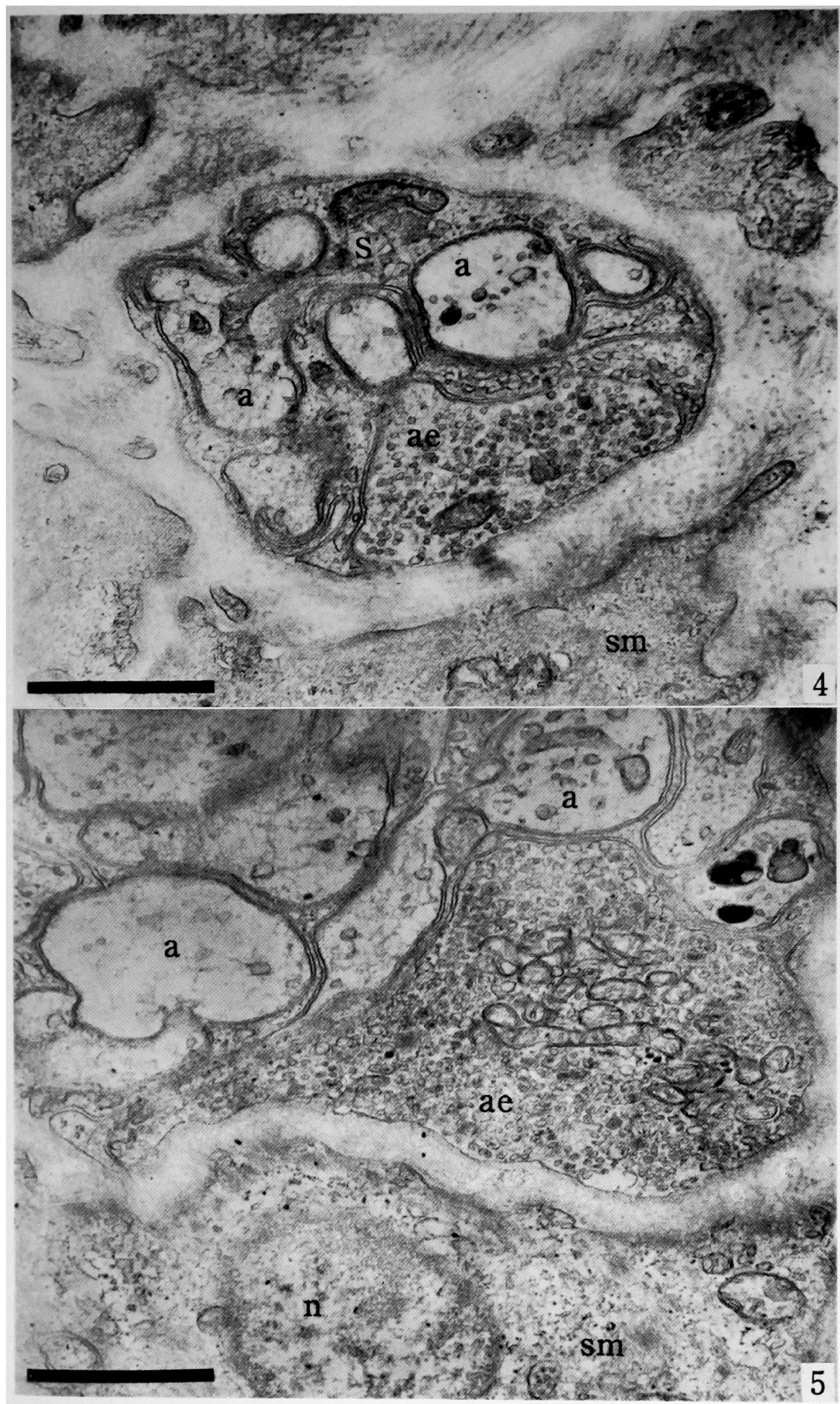

R. Honjin, A. Takahashi and Y. Tasaki 


\section{Plate III}

Fig. 6. Electron micrograph of an oblique section of a nerve bundle in the propria of mucosae of the human small intestine. In the upper part of the photographic field, there is a nerve axon (ae) which extends toward the center of the field and is exposed to the outside of the nerve bundle facing the smooth muscle cell $(\mathrm{sm})$. This nerve process shows a relatively low electron density and contains sparsely distributed vesicles and electron-dense small granules. This vesiculated nerve process may be in a depleted state. In the lower part of the nerve bundle, a nerve process which contains a large number of agranular vesicles and a few granular vesicles is seen. $\times 30,000$.

Fig. 7. Electron micrograph of an oblique section of a nerve bundle situated near a capillary in the propria of mucosae of the human small intestine. Axons seen in the center of the photograph contain many agranular synaptic vesicles and a few granulated ones. Some of the axons are about to lose their sheath in the lower left of the field. $\times 30,000$.

Fig. 8. Electron micrograph of a cross section of a small nerve bundle in the propria of mucosae of the human appendix. Close apposition between a vesiculated nerve process and an interstitial cell of $\mathrm{Cajal}$ is seen. The vesiculated nerve process contains many agranular synaptic vesicles which appear as a cluster polarized toward the closely apposed synaptic membrane. The limiting membranes of both the vesiculated nerve process and the interstitial cell of $\mathrm{Ca} \mathrm{jal}$ in the synaptic junction are separated by an interval of $180 \AA$ in width and show an increased electron density. $\times 35,000$.

Fig. 9. Electron micrograph of an oblique section of a vesiculated nerve process in the propria of mucosae of the human small intestine. Mitochondria and many agranular synaptic vesicles are seen in the vesiculated nerve process in the lower left corner of the photographic field. This vesiculated nerve process is supported by a process of the $\mathrm{Schw}$ an $\mathrm{n}$ cell (S) coming down from the upper part of the field, and simultaneously it involves a close apposition of the nerve and the interstitial cell of $\mathrm{Cajal}$ ( $\mathrm{p}$ ) which are separated by an interval of $200 \AA$ in width. The basement membrane does not extend into the synaptic cleft. $\times 30,000$. 
Plate III

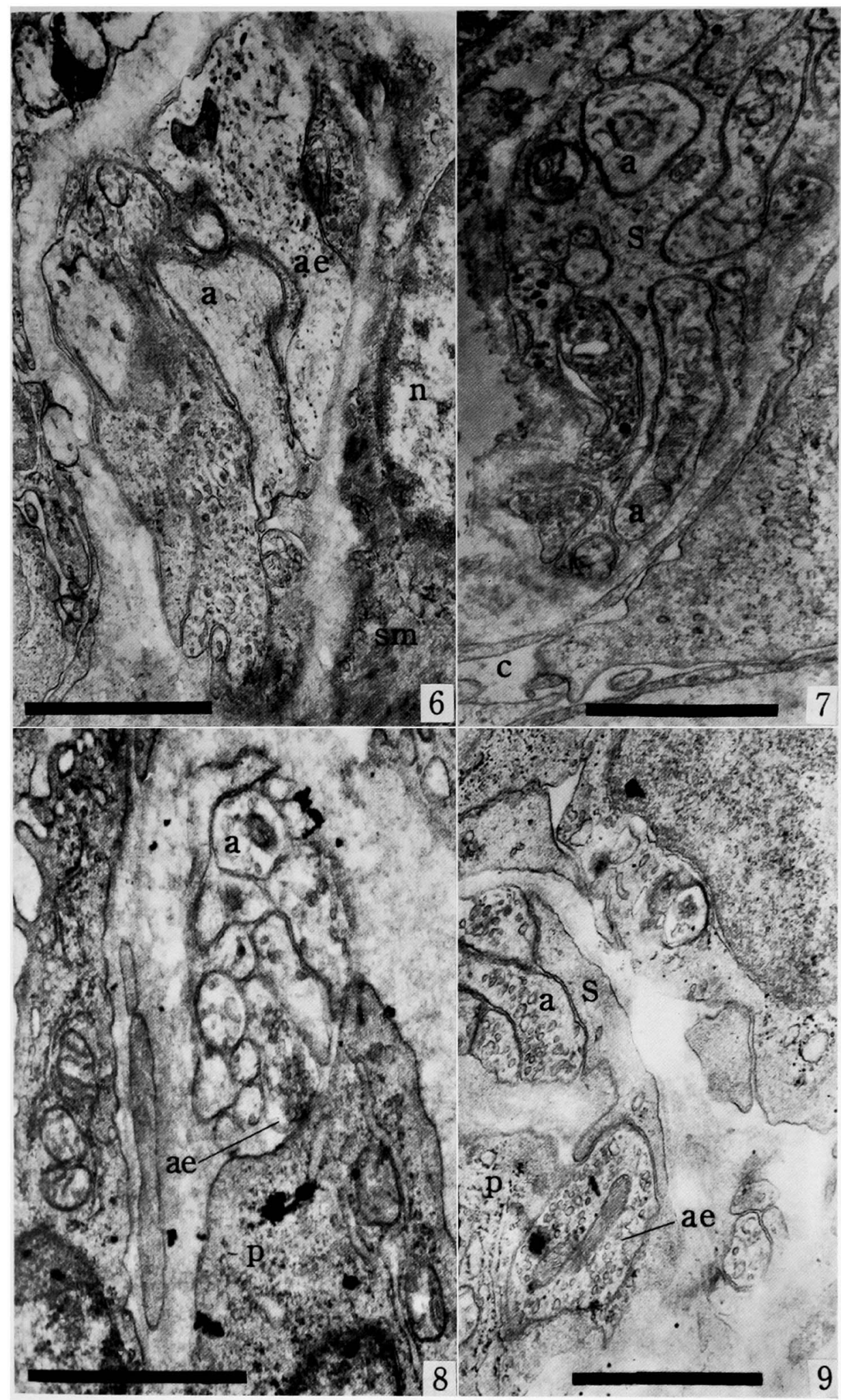

R. Honjin, A. Takahashi and Y. Tasaki 